TAPROBANICA, ISSN 1800-427X. November, 2021. Vol. 10, No. 02: pp. 80-83.

(C) Research Center for Climate Change and Department of Biology, Faculty of Mathematics \& Natural Sciences, University of Indonesia, Depok 16424, INDONESIA.

http://www.taprobanica.org

https://doi.org/10.47605/tapro.v10i2.255

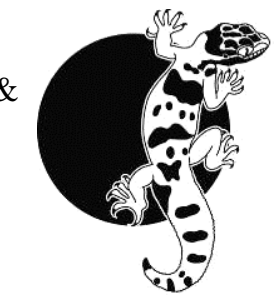

\title{
A research priority for biodiversity conservation
}

Conservation biology emerged as a scientific discipline in the mid-1980s with the explicit practical goal of conserving species and habitats (Soulé 1985). The term 'biodiversity' was coined soon after, apparently at some time during the organization of the September 1986 National Forum on Biodiversity held by the US National Academy of Sciences and the Smithsonian Institution (Takacs 1996). The science of conservation biology was quickly taken up. Journals proliferated and textbooks soon followed. Laboratories within university biology and ecology departments specialized in conservation biology. Along with a great many other young biologists and ecologists, I climbed the moral high ground and set about research to help change the future by discovering how to protect biodiversity.

Despite a moderately successful research career, I must admit to failing the practical goal of protecting biodiversity. Looking back from 2021, it is clear that conservation biology has had little impact on the forces leading to the destruction of biodiversity. Land clearing continues and the world's climate is changing. Forests, especially in developing countries, are being replaced with estate crops or cleared for agriculture. On the island of Sumatra in Indonesia, between 2000 and 2012, six primates, three of which are listed by IUCN as endangered, lost more than $50 \%$ of their forest habitat and all 22 Sumatran primate species lost some of their forest habitat (Supriatna et al. 2017). Similar impacts are evident on the island of Sulawesi (Supriatna et al. 2020). Trends like this, first emerging 20 years ago, led Whitten et al. (2001) to ask, rhetorically, what the use of conservation biology was if it could not stop something as globally significant as the loss of Indonesia's forests. Pressey et al. (2017) have recently accused conservation scientists of a collective form of displacement activityadvocating irrelevant responses to what, on the face of it; seem like the incompatible goals of protecting biodiversity and promoting human development. The Intergovernmental Science-Policy Platform on Biodiversity and Ecosystem Services (IPBES), reporting in 2019, concluded that the rate of species extinction was currently at least tens to hundreds of times higher than it has averaged over the past 10 million years, and is set to rise sharply unless the drivers of extinction are reduced. And further, that around one million animal and plant species already face extinction, and that a third of that total has arisen in the last 25 years. Conservation biology has not spent enough effort on addressing the countervailing forces of global and land use change, agricultural expansion, the imperative of generating local livelihoods, the expansion of infrastructure and settlements, and so on: the people part of the problem.

However, the need to involve people in conservation is not new. Integrated conservation and development projects (ICDPs) have been widely adopted since the late 1960s. Most suffered from a failure to recognize that trade-offs must be made, that landscapes are governed in a complex multisectoral way, that performance must be effectively monitored and adapted if necessary, and that changes occurring outside the project area can affect what happens within the project area, e.g. climate change, fluctuating global markets, etc. (Sayer et al. 2016). In 1980, IUCN, WWF and the United Nations Environment Program collaborated to publish the World Conservation Strategy (IUCN-WWF 1980), an authoritative statement on the need to reconcile the conservation of nature 
with improvements to the livelihoods of people, and the maintenance of a functioning environment to support human development. Gadgil et al. (1993) pioneered the argument that much of nature was being sustainably managed by local indigenous people. This led to recognition that indigenous knowledge should play a significant role in efforts to protect biodiversity. They showed how conservation actions have an impact on indigenous groups and argued that these people should be fully engaged in the establishment and management of protected areas.

Conservation actions take place on the ground, in geographically defined areas consisting of landscapes and seascapes. Landscapes are linked social-ecological systems. They are shaped by interactions between biological, ecological and physical processes mediated by the interventions of people (Opdam 2018). Scientists and conservation practitioners often seek transformational change in landscapes. They want problems solved-preferably within the short time frames of donor funding. However, conservation problems are societal constructions; they cannot be separated from the broader aspects of well-being, relational values, politics, etc. Conservation science would benefit from gathering evidence on how these complex social-ecological systems work and identifying processes that might influence change. Evidence in this sense is not only social and environmental data, but the knowledge of multiple actors all with different 'ways of knowing', political interests and sources of information (Evans et al. 2017). Stronger emphasis could be placed on understanding 'predictably irrational' human behavior and how to influence the decisions of those who shape the landscape (Veríssimo 2013). Many conservation scientists have argued for this agenda (Ghazoul 2007, MilnerGulland 2012, Bennett et al. 2017), but few have been able to engage for the long-term in carrying out these activities in situ, with the people whose decisions conservation scientists wish to influence.

The creation of new knowledge is always laudable and should always be encouraged. Indeed, this journal is devoted to publishing new knowledge about Asian biodiversity. Nonetheless, we already know in general terms what the goals of biodiversity conservation should be. The problem is that we don't know how to implement those goals in the complex, multi-sectoral and multi-level world of human affairs. Not enough progress has been made on how to move from knowledge of what biodiversity consists of, to how to protect it. If conservation science was part of the development process, it might be able to help steer that process rather than keep trying, unsuccessfully, to halt it. To my mind it is in the development practice process that we should be seeking the new knowledge needed to protect biodiversity.

Along with colleagues from Indonesia, Canada and the United States, I published a review in 2020 of scientific practices that have been learned from trying to balance local aspirations with global environmental values and achieve conservation outcomes (Margules et al. 2020). The five practices, some of them methods, were

(1). Understanding the socio-ecological context by getting to know the landscape we are working in, and the people who live in and use its natural resources. This involves a process of inductive research.

(2). Theories of change, which include feedback loops and trade-off, and make assumptions explicit. They are conceptually different from the logical frameworks (log frames) that have guided many conservation projects in the past.

(3). Network analysis, to identify and understand the relationships between the actors involved in the governance of landscapes.

(4). Scenario development and simulation modeling, to create both informal and formal abstractions of actual social-ecological systems to predict their performances in the real world.

(5). Multi-criteria analysis for explicit trade-offs between conservation and development outcomes.

Governance was addressed in part by practice (3) above but was not really dealt with adequately in that review. I have since come to realize that effective governance is a prerequisite for achieving improved conservation outcomes and supporting sustainable development. The term 'governance' is used to describe all the processes and interactions of an organized society over a social system. It is the way rules, norms and actions are structured, sustained, regulated, and held accountable. Thus, governance arrangements for the use of natural resources, forests for example, are extremely complex, consisting of actors from multiple sectors (governments, businesses, civil society, communities and individuals) operating at multiple levels (international, national, provincial and local). 
Dwi Amalia Sari studied aspects of the governance of forested landscapes in Indonesia in Riau (Sari et al. 2020) and South Sumatra (Sari et al. 2019). She identified policy coherence, appropriate participation and agile reflexivity as requirements for a governance structure that would be effective, i.e. fit for purpose. She evaluated policy coherence in a peat forest landscape on the Kampar Peninsula in Riau where pulp and paper companies, conservation priority areas, and local communities, are all located together; and participation and reflexivity in the Sendang landscape of South Sumatra. Sendang is a contraction of Sembilang (a protected wetland), Dangku (protected tiger habitat) and Lalan (palm oil plantations and fossil fuel extraction). She found that policies tend to be incoherent, there is inappropriate participation among all members of society and there is a lack of reflexivity in response to unforeseen developments such as pandemics and natural disasters. Ministries operate in isolation from one another and do not necessarily coordinate policies among themselves or with government institutions at lower levels. The shared goal of governance actors, the sustainable use of natural resources, ought to be accommodated adequately in legislation devolved from central government to the regions. Multi-level and multi-sectoral regulations need to be substitutable for, or complementary with, one another and stakeholders ought to be able to interact synergistically with each other.

On the Kampar Peninsula, she found that a newly introduced peat protection policy was antagonistic to existing policies, leading to policy incoherence. She made some suggestions to alleviate this problem. In Sendang, she found that two sets of governance settings coexist. By regulations, governance arrangements are highly centralized around the Ministry of Environment and Forestry. Yet, in implementation, because of complexity, companies bypass the regulations, informal patronage arrangements have a major influence on outcomes, and there is no effective intermediary institution to liaise with all governance actors.

In summary, businesses, governments at lower levels, NGOs and local communities struggle to comply with all of the conflicting or overlapping regulations that relate to the use of forested landscapes. Even if they succeed, the cost of implementation can be excessive. Improved methods for assessing governance arrangements could assist all governance actors to navigate policy complexity and avoid the potentially high costs of policies that are antagonistic to one another.

These issues are not unique to Indonesia. They are common and widespread. To realize the ambitious goals set for conservation biology in the 1980s, we need research that leads to more effective governance of the use of natural resources. As a bonus, such research would help with the development of strategies to reconcile the protection of biodiversity with improvements to the livelihoods of people, and the maintenance of a functioning environment to support human development.

\section{Acknowledgements}

I have drawn heavily on Margules et al. (2020), including material from earlier drafts that did not make it into the final manuscript, so my co-authors have contributed significantly to this editorial. However, the opinions expressed are my own and should not necessarily be attributed to them.

\section{Literature cited}

Bennet, N.J., R. Roth, S.C. Klain et al. (2017). Conservation social science: Understanding and integrating human dimensions to improve conservation. Biological Conservation, 205: 93-108.

Evans, M.C., F. Davila, A. Toomey, and C. Wyborn (2017). Embrace complexity to improve conservation decision making. Nature Ecology \& Evolution, 1: 1588.

Gadgil, M., F. Berkes, and C. Folke (1993). Indigenous knowledge for biodiversity conservation. Ambio, 22(2\&3): 151-156.

IPBES (2019): Global assessment report on biodiversity and ecosystem services of the Intergovernmental Science-Policy Platform on Biodiversity and Ecosystem Services. Brondizio, E.S., J. Settele, S. Díaz, and H.T. Ngo (eds.). IPBES secretariat, Bonn: 1148pp.

IUCN-WWF (1980). World Conservation Strategy: Living Resource Conservation for Sustainable Development. IUCN, Gland: 77pp.

Margules, C., A.K. Boedhihartono, J.D. Langston et al. (2020). Transdisciplinary science for improved conservation outcomes. Environmental Conservation, 47(4): 224-233. 
Milner-Gulland, E. (2012). Interactions between human behaviour and ecological systems. Philosophical Transactions of the Royal Society (Biological Sciences), 367(1586): 270-278.

Opdam, P. (2018). Exploring the role of science in sustainable landscape management. An introduction to the special issue. Sustainability, 10(331): 1-6.

Pressey, R.L., R. Weeks, and G.G. Gurney (2017). From displacement activities to evidence-informed decisions in conservation. Biological Conservation, 212(A): 337-348.

Sari, D.W., J. Sayer, C. Margules, and A.K. Boedhihartono (2019). Determining the effectiveness of forest landscape governance: A case study from the Sendang landscape, South Sumatra. Forest Policy \& Economics, 102(C): 17-28.

Sari, D.A., C. Margules, H.S. Lim et al. (2021). Evaluating policy coherence: A case study of peat forests on the Kampar Peninsula, Indonesia. Land Use Policy, 105(C): 105396.

Sayer, J., D. Endamana, A. Boedhihartono et al. (2016). Learning from change in the Sangha Tri-national landscape. International Forestry Review special issues: Valuing the Cameroonian Forest, 18(1): $130-139$.

Soulé, M. (1985). What is conservation biology? BioScience, 35(11): 727-734.

Supriatna, J., A.A. Dwiyahreni, N. Winarni et al. (2017). Deforestation of primate habitat on Sumatra and adjacent islands, Indonesia. Primate Conservation, 31(1): 71-82.

Supriatna, J., M. Shekelle, H.A.H. Fuad et al. (2020). Deforestation on the island of Sulawesi and the loss of primate habitat. Global Ecology \& Conservation, 24: e01205.

Takacs, D. (1996). The idea of biodiversity: Philosophies of Paradise. Johns Hopkins Press, Baltimore: 393pp.

Veríssimo, D. (2013). Influencing human behaviour: an underutilised tool for biodiversity management. Conservation Evidence, 10: 29-31.

Whitten, T., D. Holmes, and K. MacKinnon (2001). Conservation biology: A displacement activity for academia? Conservation Biology, 15(1): 1-3.

\section{Chris Margules}

Faculty of Mathematics \& Natural Sciences

Universitas Indonesia

Kampus UI, Depok 16424

Indonesia.

and

Centre for Tropical Environmental \& Sustainability Science

College of Science \& Engineering

James Cook University

Cairns Campus, Smithfield QLD 4878

Australia.

Deputy Editor: Taprobanica, the journal of Asian Biodiversity

November $22^{\text {nd }}, 2021$ 